\title{
Evolution of flow properties, plastic viscosity, and yield stress of alkali- activated fly ash/slag pastes
}

\author{
Mohammed Fouad Alnahhal ${ }^{1 *}$, Taehwan Kim¹ ${ }^{1}$ Ailar Hajimohammadi ${ }^{1}$ \\ a Centre for Infrastructure Engineering and Safety, School of Civil and Environmental Engineering, University of New South Wales, Sydney, \\ Australia
}

Received: 27 July 2020 / Accepted: 4 December 2020 / Published online: 29 December 2020

(C) The Author(s) 2020. This article is published with open access and licensed under a Creative Commons Attribution 4.0 International License.

\begin{abstract}
The development of cementless concrete is attracting increasing attention in practice and research to reduce both greenhouse gas emissions and energy consumption of concrete. Alkali-activated materials (AAMs) are one of the viable alternatives to replace Portland cement due to their lower $\mathrm{CO}_{2}$ emissions. This study investigated the evolution of rheological parameters of alkali-activated fly ash/slag pastes as a function of time. Flowability and rheological measurements were carried out to determine the fluidity, plastic viscosity, and yield stress at different time intervals. The effects of the slag content, the concentration of $\mathrm{SiO}_{2}$ in the activator, and the solution/binder ratio were considered. Based on the results, the yield stress and plastic viscosity followed an increasing trend over time coinciding with a reduction in the paste fluidity. The plastic viscosity of AAM pastes was in the range of 1.3-9.7 Pa.s and 3.9$26.3 \mathrm{~Pa} \cdot \mathrm{s}$ after $5 \mathrm{~min}$ and $45 \mathrm{~min}$ of mixing, respectively. Given the same alkali activator, the higher content of slag the paste had, the higher yield stress the paste showed. In addition, this paper confirmed that the $\mathrm{SiO}_{2} / \mathrm{Na}_{2} \mathrm{O}$ ratio in the activator had no significant effect on yield stress, but a drastic effect of this ratio was found on the plastic viscosity of the paste.
\end{abstract}

Keywords: Rheology; Alkali activated materials; Paste fluidity; Viscosity; Yield stress

\section{Introduction}

Nowadays, achieving a balance in the construction industry is essential in the current fast-growing urbanization. The progressive increasing demand for cement is foreseen as a result of the economic and population growth in developed and developing countries [1]. Hence, the development of alternative binders with lower environmental impact is recognized as one way to achieve sustainable construction. Researchers have expended significant efforts trying to develop alkali-activated materials (AAMs) as a promising alternative binder system in concrete [2]. Aluminosilicate sources such as metakaolin, blast furnace slag or fly ash are often used in AAM technology, which provides lower $\mathrm{CO}_{2}$ emissions and superior performance compared to Portland cement concrete. These benefits include better resistance against aggressive chemicals [3] and good fire resistance at elevated temperatures [4]. Moreover, fundamental differences in the rheological behaviour have been found when comparing AAM with cement-based systems [5].

Rheological properties of concrete are one of the most important areas in civil engineering communities because they affect the traditional quality of fresh and hardened concrete [6]. Significant efforts are made by researchers to understand and control the rheological behaviour of concrete from mixing to the setting, and to mimic the shear behaviour during real applications [7]. At the fresh state from mixing to casting, a relatively high shear rate would be applied due to mixing, casting, pumping, and compacting processes. Thus, the yield stress and plastic viscosity are very important parameters to correlate these properties with the workability/flowability [8]. The traditional so-called flow sweep test has been widely used to characterise the flowability and rheological parameters, which are referred to as plastic viscosity and yield stress [9].

Although AAMs have been studied by many researchers as an alternative "green" concrete, very limited studies have dealt with its rheological behaviour and flow properties [10-13]. The different rheological behaviour of AAM paste suggests that a more efficient technology is required for the enhancement of the flow behaviour compared to the conventional methods that have been developed for the traditional Portland cement-based systems. In AAM systems, the highly viscous solutions typically used for the activation of the precursors result in very weak interactions between particles. Consequently, the activator's chemical composition and its viscosity govern the overall rheological behaviour of the system, where a slow flocculation process is observed due to the dissipation of the particle kinetic energy [14].

\footnotetext{
* Corresponding author: Mohammed Fouad Alnahhal, Email: m.alnahhal@unsw.edu.au
} 
To study the evolvement of the rheology of AAM pastes, including the yield stress, plastic viscosity and their evolution as a function of the paste age, the simple flow curve test at different elapsed times seem to be effective. Further, using these tests for the characterisation of the rheological parameters may provide insights into the effects of different interactions between the suspended particles and the solution during the shearing in AAM pastes. The thorough interpretation of this behaviour in the case of such complex systems is not straightforward using the flow curve test due to the chemical and physical processes. Therefore, other techniques might be more critical for the fundamental understanding, such as the small-amplitude oscillatory shear test [15]. However, the flow curve is a primary test to study the rheological properties of various suspended materials and thus, this test is selected in this study. It should be noted that the influence of the various parameters used in AAM pastes on the overall rheological properties of the AAM paste has yet to be fully understood in the literature. Filling the knowledge gaps that currently exist concerning the effect of using highly viscous activators is essential for the widespread acceptance of AAM technology. Moreover, the majority of previous studies have dealt with the flow properties of AAM pastes made of solely either a low-calcium precursor such as Class $F$ fly ash and metakaolin $[5,13,16]$, or calcium-rich slags [12, 17]. On the other hand, very limited studies have investigated the rheological behaviour of binary systems [18].

In this research, we will focus on the effect of the viscosity of the activator along with the slag content on the plastic viscosity and yield stress of the AAM paste. The effect of different parameters was assessed including the slag content as well as the $\mathrm{SiO}_{2} / \mathrm{Na}_{2} \mathrm{O}$ ratio and the volume of the alkaline activator. In addition, the evolution of rheological parameters and the paste fluidity of AAMs were investigated at different elapsed times.

\section{Materials and methods}

\subsection{Materials}

In this study, two types of industrial by-products were utilized, namely, fly ash (FA) and ground granulated blast furnace slag (GGBFS). The chemical composition of FA and GGBFS is shown in Table 1. The specific gravities of FA and GGBFS are 2.1 and 2.8 , respectively.

The alkaline activator was a mixture of sodium hydroxide $(\mathrm{NaOH})$ and sodium silicate solution. The commercial sodium silicate solution had the following composition: $14.7 \%$ of $\mathrm{Na}_{2} \mathrm{O}, 29.4 \%$ of $\mathrm{SiO}_{2}, 55.9 \%$ of water (by weight). The $\mathrm{NaOH}$ solution with $30 \%$ concentration (Molarity $\approx 10 \mathrm{M}$ ) was prepared by dissolving $400 \mathrm{~g}$ of $\mathrm{NaOH}$ pellets per litre of solution.
Table 1. Chemical Composition of FA and GGBFS.

\begin{tabular}{|l|l|l|}
\hline Chemical compositions (\%) & FA & GGBFS \\
\hline $\mathrm{SiO}_{2}$ & 66.56 & 31.52 \\
\hline $\mathrm{Al}_{2} \mathrm{O}_{3}$ & 22.47 & 12.22 \\
\hline $\mathrm{CaO}$ & 1.64 & 44.53 \\
\hline $\mathrm{Fe}_{2} \mathrm{O}_{3}$ & 3.54 & 1.14 \\
\hline $\mathrm{MgO}$ & 0.65 & 4.62 \\
\hline $\mathrm{MnO}$ & 0.06 & 0.36 \\
\hline $\mathrm{Na}_{2} \mathrm{O}$ & 0.58 & 0.21 \\
\hline $\mathrm{K}_{2} \mathrm{O}$ & 1.75 & 0.33 \\
\hline $\mathrm{P}_{2} \mathrm{O}_{5}$ & 0.11 & 0.02 \\
\hline $\mathrm{TiO}_{2}$ & 0.88 & 1.03 \\
\hline $\mathrm{SO}_{3}$ & 0.1 & 3.24 \\
\hline $\mathrm{LOI}$ & 1.66 & 0.79 \\
\hline
\end{tabular}

\subsection{Mixture design}

The FA, GGBFS, and chemical activators were added in the mixes with different dosages to maintain prescribed alkali dosages $(\mathrm{M}+)$ and alkali moduli (Ms) as shown in Table 2 and 3. $\mathrm{M}+$ is the mass ratio of $\mathrm{Na}_{2} \mathrm{O}$ in the activating solution (i.e. $\mathrm{Na}_{2} \mathrm{O}$ from $\mathrm{NaOH}$ solution $+\mathrm{Na}_{2} \mathrm{O}$ from sodium silicate solution) to the binder dry mass. Ms is the mass ratio of $\mathrm{SiO}_{2} / \mathrm{Na}_{2} \mathrm{O}$ in the alkali activator.

In the first Series (see Table 2), the FA was replaced by GGBFS at levels of $10 \%, 20 \% 30 \%$ and $40 \%$ by volume, while the solution/binder (by volume) ratio and Ms were kept constant at 0.9 and 1.0, respectively, to study the effect of GGBFS on the flow properties and rheological behaviour. The volumetric solution/binder ratio was shown to most strongly influence the rheological parameters of the paste [19]. Therefore, the GGBFS replacement was done in volume basis to maintain the solution/binder at 0.9 .

Table 2. Mixture proportions for Series I.

\begin{tabular}{|c|c|c|c|c|}
\hline Mixture & S10 & S20 & S30 & $\mathrm{S} 40$ \\
\hline Replacement level (vol.) & $10 \%$ & $20 \%$ & $30 \%$ & $40 \%$ \\
\hline GGBFS $\left(\mathrm{kg} / \mathrm{m}^{3}\right)$ & 147 & 295 & 442 & 589 \\
\hline Fly Ash $\left(\mathrm{kg} / \mathrm{m}^{3}\right)$ & 994 & 884 & 773 & 663 \\
\hline $\mathrm{NaOH} 10 \mathrm{M}\left(\mathrm{kg} / \mathrm{m}^{3}\right)$ & 185 & 185 & 185 & 185 \\
\hline Sodium silicate $\left(\mathrm{kg} / \mathrm{m}^{3}\right)$ & 300 & 300 & 300 & 300 \\
\hline Additional Water $\left(\mathrm{kg} / \mathrm{m}^{3}\right)$ & 135 & 135 & 135 & 135 \\
\hline Solution/binder (by vol.) & 0.9 & 0.9 & 0.9 & 0.9 \\
\hline Solution/binder (by wt.) & 0.54 & 0.52 & 0.51 & 0.49 \\
\hline w/s (weight) & 0.32 & 0.31 & 0.31 & 0.3 \\
\hline $\mathrm{SiO}_{2}\left(\mathrm{~kg} / \mathrm{m}^{3}\right)$ & 88 & 88 & 88 & 88 \\
\hline $\mathrm{Na}_{2} \mathrm{O}\left(\mathrm{kg} / \mathrm{m}^{3}\right)$ & 88 & 88 & 88 & 88 \\
\hline $\mathrm{Ms}, \mathrm{SiO}_{2} / \mathrm{Na}_{2} \mathrm{O}$ (by wt.) & 1.00 & 1.00 & 1.00 & 1.00 \\
\hline $\mathrm{SiO}_{2} / \mathrm{Na}_{2} \mathrm{O}$ (molar ratio) & 1.03 & 1.03 & 1.03 & 1.03 \\
\hline $\mathrm{M}+, \mathrm{Na}_{2} \mathrm{O} /$ binder (\% wt.) & 7.7 & 7.5 & 7.2 & 7.0 \\
\hline
\end{tabular}

Table 3 summarizes Series II and Series III. In the second Series, the volumetric solution/binder ratios of 1.0 and 1.1 were tested for the mix containing 20\% GGBFS and Ms of 1.0. In the third Series, the effect of $\mathrm{SiO}_{2} / \mathrm{Na}_{2} \mathrm{O}$ was examined by using Ms of 1.1, 1.2, 1.3 and 1.5, while keeping the solution/binder and GGBFS content constant at 0.9 and $20 \%$, respectively. 
Table 3. Mixture proportions for Series II and Series III.

\begin{tabular}{|c|c|c|c|c|c|c|}
\hline \multirow{2}{*}{ Mixture } & \multicolumn{2}{|c|}{ Series II } & \multicolumn{4}{|c|}{ Series III } \\
\hline & SB1.1 & SB1.0 & Ms1.1 & Ms1.2 & Ms1.3 & Ms1.5 \\
\hline Replacement level (vol.) & $20 \%$ & $20 \%$ & $20 \%$ & $20 \%$ & $20 \%$ & $20 \%$ \\
\hline GGBFS $\left(\mathrm{kg} / \mathrm{m}^{3}\right)$ & 267 & 280 & 295 & 295 & 295 & 295 \\
\hline Fly Ash $\left(\mathrm{kg} / \mathrm{m}^{3}\right)$ & 800 & 840 & 884 & 884 & 884 & 884 \\
\hline $\mathrm{NaOH} 10 \mathrm{M}\left(\mathrm{kg} / \mathrm{m}^{3}\right)$ & 165 & 173 & 165 & 145 & 127 & 93 \\
\hline Sodium silicate $\left(\mathrm{kg} / \mathrm{m}^{3}\right)$ & 270 & 281 & 324 & 356 & 386 & 442 \\
\hline Additional Water $\left(\mathrm{kg} / \mathrm{m}^{3}\right)$ & 218 & 180 & 132 & 127 & 121 & 110 \\
\hline Solution/binder (by vol.) & 1.1 & 1 & 0.9 & 0.9 & 0.9 & 0.9 \\
\hline Solution/binder (by wt.) & 0.61 & 0.57 & 0.53 & 0.53 & 0.54 & 0.55 \\
\hline w/s (weight) & 0.39 & 0.36 & 0.31 & 0.31 & 0.31 & 0.31 \\
\hline $\mathrm{SiO}_{2}\left(\mathrm{~kg} / \mathrm{m}^{3}\right)$ & 79 & 83 & 95 & 105 & 114 & 130 \\
\hline $\mathrm{Na}_{2} \mathrm{O}\left(\mathrm{kg} / \mathrm{m}^{3}\right)$ & 79 & 83 & 88 & 88 & 88 & 88 \\
\hline $\mathrm{Ms}, \mathrm{SiO}_{2} / \mathrm{Na}_{2} \mathrm{O}$ (wt. ratio) & 1.00 & 1.00 & 1.10 & 1.20 & 1.30 & 1.5 \\
\hline $\mathrm{SiO}_{2} / \mathrm{Na}_{2} \mathrm{O}$ (molar ratio) & 1.03 & 1.03 & 1.11 & 1.23 & 1.34 & 1.52 \\
\hline $\mathrm{M}+, \mathrm{Na}_{2} \mathrm{O} /$ binder (\% wt.) & 7.5 & 7.5 & 7.5 & 7.5 & 7.5 & 7.5 \\
\hline
\end{tabular}

\subsection{Mixing and testing procedures \\ 2.3.1 Mixing procedure}

The mixing protocol, mixture proportions, and mixture composition are important factors that affect the rheology of cementitious pastes [20]. For a given mixture, all dry FA and GGBFS were first pre-blended for $1 \mathrm{~min}$. Liquid activators were prepared before mixing with the binders and allowed to cool down to ambient temperature. The activators used were prepared on the same day of mixing to avoid precipitation of solid sodium metasilicate hydrates [21]. The activator and the binders were then mixed at $180 \mathrm{rpm}$ for $30 \mathrm{sec}$, followed by $280 \mathrm{rpm}$ for $60 \mathrm{sec}$. The homogeneously mixed paste was used for the rheological measurements at elapsed times of 5, 30 and $45 \mathrm{~min}$. In this study, all AAM mixes were prepared using the Renfert vacuum mixer to remove the entrapped air bubbles.

\subsubsection{Paste fluidity}

The flow table test was used to determine the effect of different parameters on the fluidity of the AAM pastes. A cone-geometry was used for the test with $70 \mathrm{~mm}$ top diameter, $100 \mathrm{~mm}$ bottom diameter and $50 \mathrm{~mm}$ height. The test on the fresh paste was carried out at different elapsed times after mixing in order to study the change in the spread diameter due to stiffening of AAM pastes. At different intervals, the paste was poured into the cone, and then the cone was lifted as slowly as possible to minimize inertial effects [21]. Due to the high fluidity, the pastes were allowed to spread on the flow table without dropping the table, and the average diameter of the spread was measured after 1 min.

\subsubsection{Flow sweep}

Discovery Hybrid Rheometer (DHR-2) from TA Instrument was used to perform the flow sweep to determine the plastic viscosity and yield stress of the AAM pastes. A sandblasted concentric cylinder geometry was used. The inner radius of the cup cylinder is $15.16 \mathrm{~mm}$, and the radius of the bob cylinder is $14.00 \mathrm{~mm}$, making the gap width as $1.16 \mathrm{~mm}$. Each batch to be tested using the rheometer was prepared following the mixing process described in Section 2.3.1. The homogeneously mixed paste was immediately used for testing. The testing procedure consists of pre-shearing the paste at $100 \mathrm{~s}^{-1}$ for $60 \mathrm{~s}$ followed by $60 \mathrm{~s}$ resting time.
Rotational shear rates of $45-100 \mathrm{~s}^{-1}$ for $30-60 \mathrm{~s}$ were used in the AAMs by many researchers to achieve a well-dispersed state and to ensure that all samples were in the same reference condition [14, 22-24]. This range is lower than the range used in previous studies on cement paste because cement particles form flocs when in contact with water, and hence, require more time to break-down the forming flocs to achieve a well-dispersed state. Therefore, the equilibrium state in AAMs is achieved at lower shear rates and times, which is in line with previous research by Favier, et al. [5]. Moreover, the previous study on AAM recommended a relaxation period before each rheological measurement to avoid any residual stresses that are transformed from the previous stage (i.e. transferring the paste to the measurement cell and/or the pre-shear in this study) [25]. Therefore, $60 \mathrm{~s}$ resting time was chosen for this study, matching with some previous studies [26-29].

After the $60 \mathrm{~s}$ resting time, logarithmic flow sweep was performed (using 10 points per decade) by ramping up the shear rate from $0.1 \mathrm{~s}^{-1}$ to $100 \mathrm{~s}^{-1}$. The thixotropic behaviour of cementitious materials implies that higher viscosity would be obtained when the rate of shear strain is more quickly increased. Hence, to ensure the stable shear stress and the plastic viscosity at the applied shear strain, trial tests (three interval thixotropy tests) on the plastic viscosity of AAM paste were performed (the results were not shown in this paper). A total time of $10 \mathrm{~s}$ was sufficient to achieve a constant value of the plastic viscosity, which is consistent with several previous studies $[10,18,30]$. Therefore, at each step (i.e. at each shear rate), the instrument was set to make an equilibrium time of $5 \mathrm{~s}$ as well as an averaging time of $5 \mathrm{~s}$ to calculate the plastic viscosity and shear stress at each step. All measurements were made at $25^{\circ} \mathrm{C}$. For ensuring the repeatability of measurements, three identical samples were independently prepared for each of S10, S20, and Ms1.2 and good repeatability was observed from these selected mixes (the result was not shown in this paper.). It should be noted that the yield stresses and the plastic viscosities were determined using a Bingham model. A Bingham straight-line was fitted using the ascending line fitted using 20 points between 0.1 and $10 \mathrm{~s}^{-1}$ to minimize the effect of the fast reaction of AAM pastes. 


\section{Results and discussion}

\subsection{Paste fluidity}

The influence of mix design parameters on the fluidity of AAM pastes was examined. After mixing, all pastes showed a spread diameter of $240 \mathrm{~mm}$, which indicates the high fluidity of the mixtures, as shown in Fig. 1. This diameter was gradually decreased to $120 \mathrm{~mm}$ over time, which indicates zero fluidity and a stiff paste. However, the hardening time was varied among the pastes, depending on the GGBFS content, solution/binder ratio and Ms ratio. According to Fig. $1 a$, the fluidity was decreased sharply overtime when the GGBFS content was increased from $10 \%$ to $40 \%$. It should be noted that GGBFS has a much higher content of $\mathrm{CaO}$ than FA as shown in Table 1. Oderji, et al. [31] stated that the presence of more $\mathrm{CaO}$ in the mixture leads to a higher loss of fluidity over time. This could be attributed to the higher rate of gel formation at an early age for pastes containing higher amounts of GGBFS. The fluidity varied slightly by changing the chemical composition and the volume of the activator, as shown in Fig. $1 \mathrm{~b}$ and $\mathrm{c}$. For instance, the spread diameter of the paste made of Ms 1.5 was slightly lower than the other mixtures, but there was no distinct trend observed in terms of the effect of the $\mathrm{SiO}_{2}$ concentration on fluidity in this study. Previous studies showed that the effect of Ms on the early age stiffening is insignificance [32, 33]. The setting and dissolution of starting materials of the paste are mainly dependent on $\mathrm{OH}^{-}$groups' presence. In this study, the amount of $\mathrm{OH}$ - group in activators were fixed despite the variation in the silica modulus, which may explain the less sensitive spread diameter in terms of the variation of Ms values from 1.0 to 1.5 .

\subsection{Evolution of plastic viscosity and yield stress}

AAM paste behaves like a non-Newtonian fluid and its shear stress curve fits well with Bingham model [10, 34], as shown in the following equation.

$$
\tau=\tau_{o}+\eta \dot{\gamma}
$$

where $\eta, \tau, \tau_{0}$, and $\dot{\gamma}$ are the plastic viscosity (Pa.s), shear stress $(\mathrm{Pa})$, yield stress $(\mathrm{Pa})$ and shear rate $\left(\mathrm{s}^{-1}\right)$, respectively. $\mathrm{A}$ Bingham straight-line was observed from the ascending line fitted using 20 points between 0.1 and $10 \mathrm{~s}^{-1}$. The yield stress obtained from the ascending and descending curves is shown in Fig. 2. As can be seen, the value of the ascending curve was slightly higher than the descending one except for the mixes S30, S40, Ms1.3 and Ms1.5. The higher yield stress of the descending curve in the latter mixes could be attributed to the effect of hydration/geopolymerisation, where the descending curve requires double elapsed time (up to $12 \mathrm{~min}$ ) compared to the ascending one. Therefore, to determine the plastic viscosity and yield stress of the pastes, the ascending shear rate-shear stress profile was chosen for analysis. The descending curve doubles the measurement time and can increase the potential effect of chemical changes on the rheological parameters.

At ambient temperature, the changes in the plastic viscosity and yield stress are dependent on the amount of GGBFS as well as the composition of the alkaline activator. The effect of different factors on the evolution of plastic viscosity and yield stress as a function of time is discussed in the following sections.

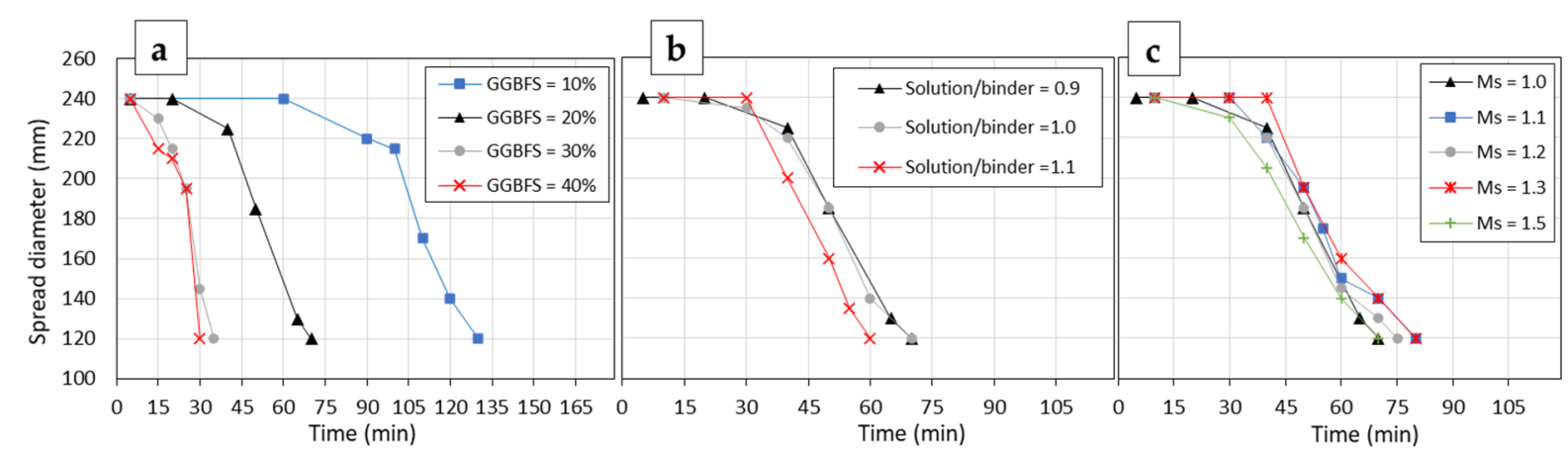

Figure 1. Spread diameter of the pastes at different intervals after mixing. (a) GGBFS 10\%-40\%, (b) solution/binder 0.9-1.1 and (c) Ms 1.0-1.5.

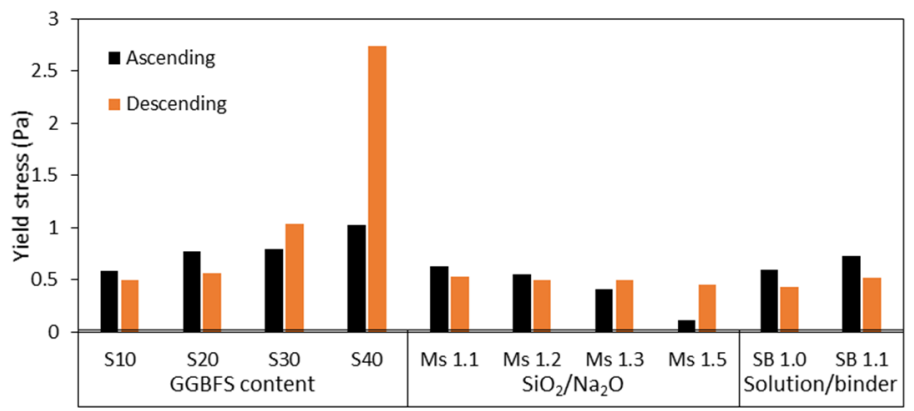

Figure 2. Bingham model yield stress of AAM pastes obtained from the ascending and descending curves. 

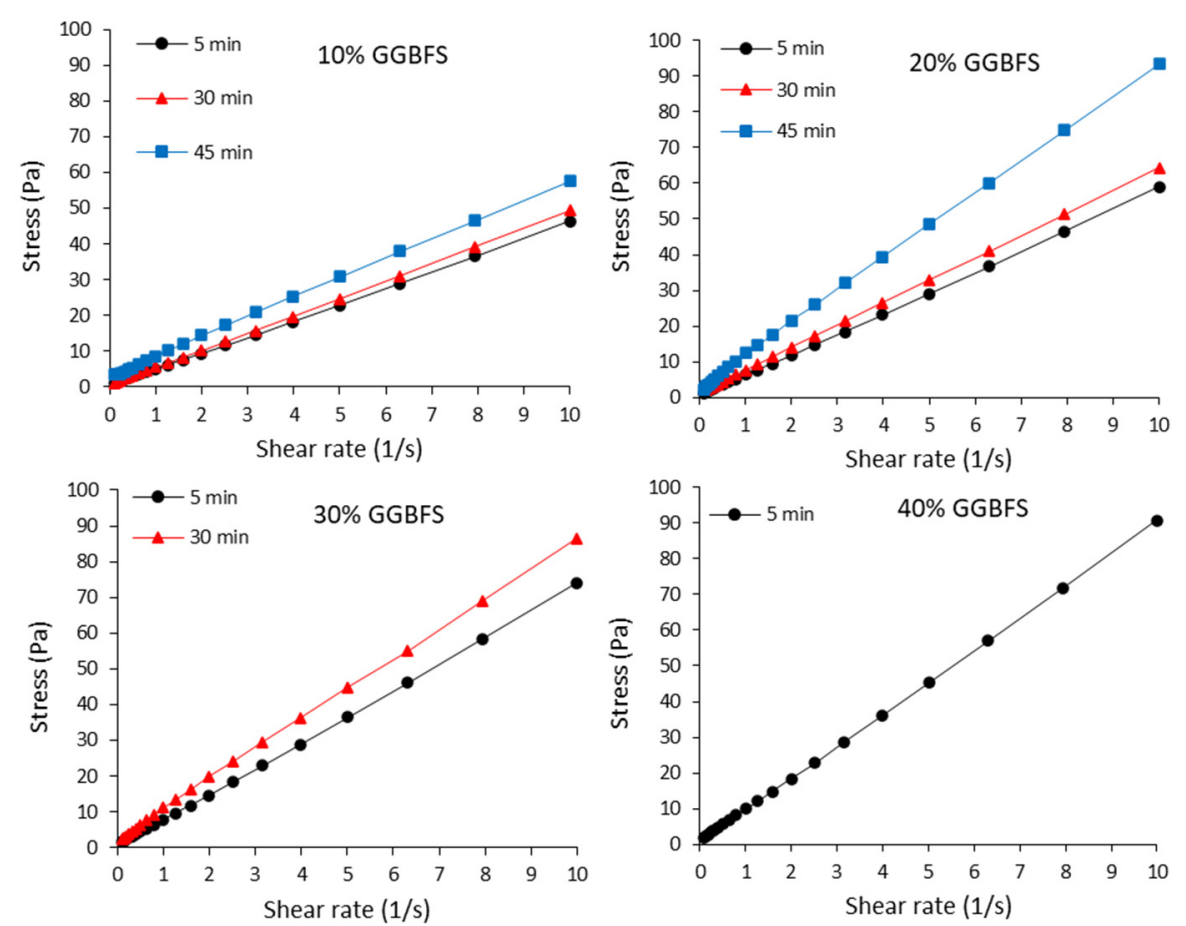

Figure 3. Flow sweep curve for pastes containing 10\%-40\% GGBFS.

\subsubsection{Effect of GGBFS}

Flow sweep curves for pastes containing 10\%-40\% GGBFS are shown in Fig. 3. Plastic viscosities and yield stresses for AAM pastes were calculated at elapsed times of 5, 30 and $45 \mathrm{~min}$ after mixing. Fig. 4 and Fig. 5 show the yield stress and plastic viscosity values for each mixture at different elapsed times. At $5 \mathrm{~min}$, the yield stress was increased from $0.59 \mathrm{~Pa}$ to $1.03 \mathrm{~Pa}$ when the GGBFS content was increased from $10 \%$ to $40 \%$. In these mixes, the GGBFS contents were altered while all other parameters were kept constant. The increasing trend in the yield stress could be due to i) the effect of particle shape in controlling the rheological properties [18, 35] and ii) the accelerated chemical reaction due to the higher GGBFS content. The yield stress and the plastic viscosity were measured in $\sim 4 \mathrm{~min}$ after the initial pre-shearing. Therefore, the effect of the chemical reaction in this short time may be negligible and the particle shape may govern the increased trend though further research will be required.

In case of concentrated cementitious suspensions, because of the very small separation distance between particles and the complex shape of the particles' surface, the overall viscosity of the system is influenced by the viscous force of the suspending fluid as well as the particle-particle interactions [36]. When a shear force is imposed on the AAM paste, this shear causes the complex relative motion of particles, so that the particle shape (or roughness) contributes to the rheological behaviour of the paste. GGBFS is well-known to have an irregular particle shape compared to the spherical shape of fly ash. Consequently, an increase in the interparticle surface interaction is expected by increasing the content of angular GGBFS, which in turn contributes to the increase in the yield stress and plastic viscosity. At longer reaction time, e.g. at $45 \mathrm{~min}$, an increase in the yield stress was recorded due to the formation of reaction products. It should be noted that

the rapid setting at higher slag contents limited the measurements, where it could not be conducted at $45 \mathrm{~min}$ for $30 \%$ GGBFS, and 30 and 45 min for $40 \%$ GGBFS.

Fig. 4 and Fig. 5 show that the plastic viscosity and the yield stress for each mixture increase over time. These increases in the rheological parameters would be due to the reaction of AAM pastes that results in the geopolymeric network growth $[17,25,37]$. It should be noted that the higher content of GGBFS the AAM paste had, the higher increasing rate of rheological parameters it showed over time. This could be attributed to the accelerated reaction in the presence of a higher amount of calcium provided by the GGBFS. Mehdizadeh and Kani [17] reported that the calcium presence results in an accelerated reaction leading to more early age gel formation and rigid interactions. As a result, the mix with $10 \%$ GGBFS, for example, showed a negligible growth in the rheological parameters over time, suggesting the absence of early-age rigid interactions between particles.

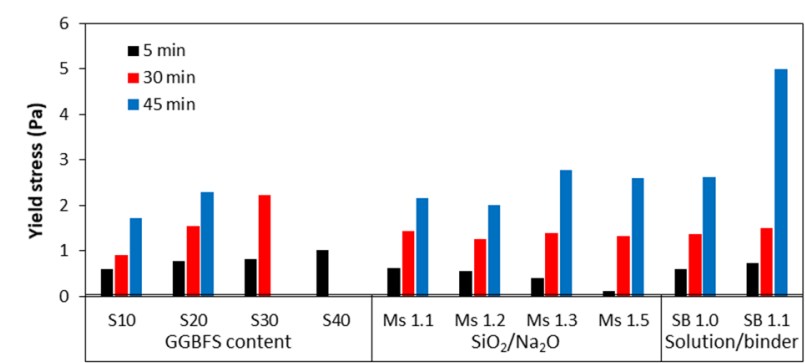

Figure 4. Yield stress of AAM pastes at different elapsed times. 


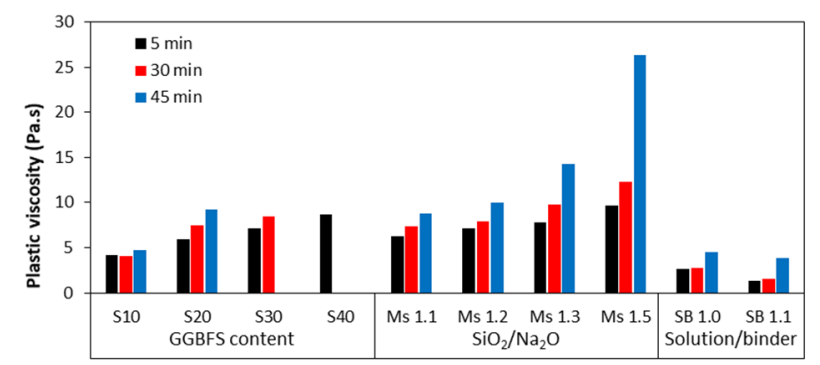

Figure 5. Plastic viscosity of AAM pastes at different elapsed times.

\subsubsection{Effect of silica modulus}

The effect of $\mathrm{SiO}_{2} / \mathrm{Na}_{2} \mathrm{O}$ ratio on the evolvement of the yield stress and plastic viscosity over time was tested, and the results are shown in Fig. 4, 5 and 6 . The results show that, at $5 \mathrm{~min}$, the increase in the concentration of the $\mathrm{SiO}_{2}$ in the activator resulted in a decrease in the yield stress from 0.77 $\mathrm{Pa}$ to $0.12 \mathrm{~Pa}$. This indicates the minor effect of silicate concentration on the yield stress at reaction times less than $45 \mathrm{~min}$ in this study. The yield stress is known to be controlled by the interactions between particles. At a fixed fraction of solids, the yield stress of cementitious materials is controlled by the extent of flocculation of the particles that are formed as a result of the colloidal interactions, such as Van der Waal forces, and the minor contribution of the reaction products formed between particles at the very early age $[38,39]$. The formation of early age reaction products in AAM systems and the consequent interparticle interactions are mainly influenced by the availability of alkalis $\left(\mathrm{Na}_{2} \mathrm{O}\right)$ due to the higher solubility of aluminosilicates at very high alkalinity [33, 37]. In this study, the $\mathrm{Na}_{2} \mathrm{O}$ content was identical in the pastes made of different silica modulus ratios. As a result, the binder dissolution and subsequent gel formation at the very fresh state would be similar for these mixes. Therefore, the minor effect of the silica modulus on the yield stress of the pastes is expected as shown in the experimental results. Puertas, et al. [12] also found that the $\mathrm{SiO}_{2} / \mathrm{Na}_{2} \mathrm{O}$ ratio had no significant effect on yield stress at early ages.

On the other hand, increasing the silica modulus from 1.0 to 1.5 resulted in a clear increase in the plastic viscosity from 5.9 Pa.s to 9.7 Pa.s. This can be explained by the viscous effect of silicate solutions. To maintain the silica modulus at higher ratios, an increased volume of the sodium silicate solution was required, which in turn contributed to the increase in the overall viscosity of the paste. Furthermore, AAM pastes can be considered suspensions of precursors in a suspending alkaline activator called a Newtonian solution [5]. An interstitial fluid (alkaline activator) exists between the particles despite the high-volume fraction of solids. Therefore, at a fixed volume fraction of solids, the viscosity of the system proportionally increases by increasing the viscosity of the suspending fluid. Moreover, the low yield stress of AAM pastes reflects the dominance of the viscous effect, and the colloidal interactions between particles are negligible [5, 36]. Therefore, at the very early age of the fresh AAM pastes, the plastic viscosity of the paste is mainly controlled by the viscosity of the activator because the influence of the precursors seems to be identical for mixtures in Series II due to the fixed amount of GGBFS and FA in these mixtures.

\subsubsection{Effect of solution/binder ratio}

In general, at $5 \mathrm{~min}$, the increase of the solution/binder ratio from 0.9 to 1.1 resulted in a decrease in the yield stress and plastic viscosity, as shown in Figs. 4 and 5 . This could be attributed to the reduction in the volume fraction of solids in the suspending fluid [19]. The particle spacing increases due to the increase in the volume of the solution. This increased particle spacing would result in a reduction in particle-particle interactions [19]. Therefore, the increased volume of the solution decreases the yield stress and viscosity of the suspensions, as shown in Fig. 7.

In cement-based systems, the lower yield stress is normally observed when increasing the water/cement ratio due to the increased particle spacing [40]. A similar trend was observed for AAM pastes at $5 \mathrm{~min}$ as explained in the previous paragraph. However, it is very interesting to note that a different behaviour was observed at $45 \mathrm{~min}$, where the yield stress showed an increasing trend by increasing the solution/binder ratio. The factors that likely to affect the yield stress evolution over time are: i) the viscosity of the suspending fluid and its influence on the interparticle forces and flocculation, and ii) the formation of interparticle reaction products. At the solution/binder ratios investigated in this paper, similar dissolution and formation of hydration products are expected due to the fixed $\mathrm{SiO}_{2} / \mathrm{Na}_{2} \mathrm{O}$ and $\mathrm{Na}_{2} \mathrm{O} /$ binder ratios for the mixes made of solution/binder ratios of 0.9-1.1. Nevertheless, slower flocculation is expected for the pastes activated with a higher viscosity activator than that from the paste with a lower viscosity activator. This is because, when the particles are drawn together due to the interparticle colloidal interactions, the higher viscous activator causes the more dissipation of the kinetic energy of particles than the lower viscous activator does. Therefore, the AAM pastes activated with the higher viscous activator seem to have the delayed flocculation process, which delays the yield stress development over time [41]. It is noteworthy that the comparison in Series II may not be straightforward due to the combined effect of both the activator concentration and the volume fraction of particles.

To study the effect of the activator concentration, the Newtonian viscosities of the activating solutions used in all mixes was measured, and the results can be found in Table 4 . The viscosity of activators used for $\mathrm{S} 20$ (solid/binder $=0.9$ ), SB1.0, and SB1.1 were 0.0110 Pa.s, 0.0085 Pa.s, and 0.0055 Pa.s respectively. To make AAM pastes with different solution/binder ratios but with similar $\mathrm{Ms}$ and $\mathrm{Na}_{2} \mathrm{O}$ /binder ratios, additional water was added to the activator to achieve solution/binder ratios of 1.0 and 1.1. The additional water leads to a decrease in the activator concentration. Consequently, the increase in water content that had a relatively lower viscosity led to a reduction in the overall viscosity of the activator. As explained in the previous paragraph, the decrease in viscosity for S10, SB1.0, and SB1.1 was inversely proportional to the yield stress of corresponding mixtures at $45 \mathrm{~min}$ (see Fig. 3). 

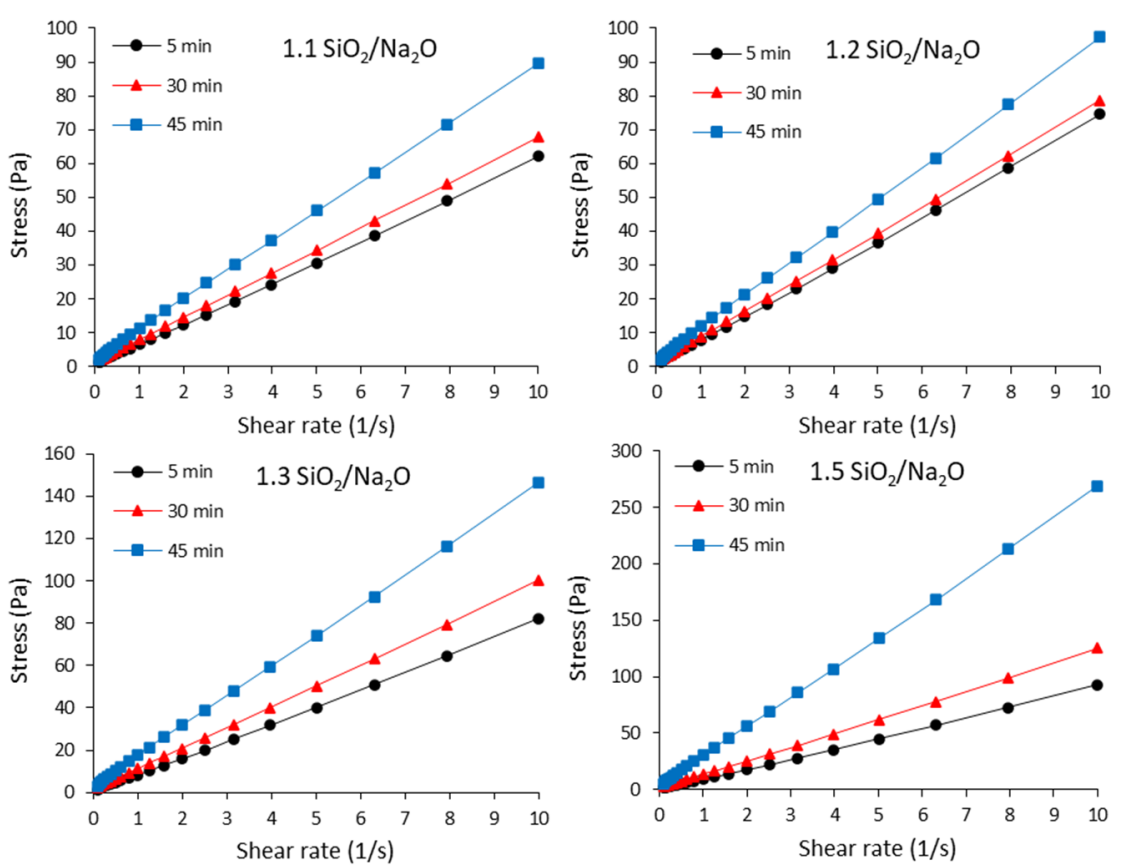

Figure 6. Flow sweep curve for pastes at different $\mathrm{SiO}_{2} / \mathrm{Na}_{2} \mathrm{O}$ ratios.
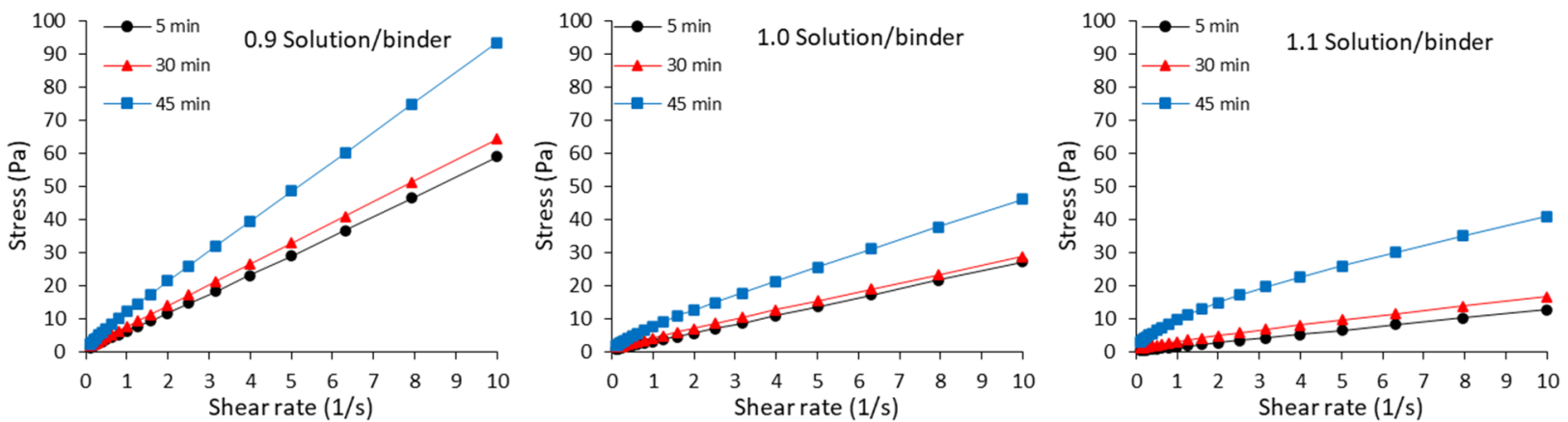

Figure 7. Flow sweep curve for pastes at different solution/binder ratio.

Table 4. The viscosity of the activator solutions used in AAM pastes.

\begin{tabular}{|c|c|c|c|c|c|c|c|c|c|c|}
\hline \multirow[t]{2}{*}{ Solution } & \multicolumn{4}{|c|}{ GGBFS replacement level } & \multicolumn{4}{|c|}{$\mathrm{SiO}_{2} / \mathrm{Na}_{2} \mathrm{O}$} & \multicolumn{2}{|c|}{ Solution/binder } \\
\hline & $10 \%$ & $20 \%$ & $30 \%$ & $40 \%$ & 1.1 & 1.2 & 1.3 & 1.5 & 1.0 & 1.1 \\
\hline $\begin{array}{l}\text { Newtonian } \\
\text { viscosity }(\mathrm{Pa} \cdot \mathrm{s})\end{array}$ & 0.0110 & 0.0110 & 0.0110 & 0.0110 & 0.0125 & 0.0145 & 0.0163 & 0.0213 & 0.0085 & 0.0055 \\
\hline
\end{tabular}

This observation indicated that, at $45 \mathrm{~min}$, the viscous effect is dominating and becomes more significant in controlling the flocculation process. Consequently, a higher evolution of the yield stress over time was observed for the pastes made of activator of lower viscosity. This observation is valid for within the tested range, and a different trend could be obtained at a very low fraction of solids.

\section{Conclusions}

In this study, the mechanism of interactions between precursor particles suspended in an alkaline silicate solution was shown to be different compared to those found in the literature for cement-based systems. To study these mechanisms, the effect of GGBFS content, and the volume and chemical composition of alkaline activator on the rheological behaviour and flow properties of AAM pastes, was investigated. The procedure of the rheological tests used in this paper may not be identical to the shearing procedure of real concrete. However, this paper mainly focused on the trend and the change in the yield stress and the plastic viscosity as a function of time and the mixture designs. Thus, the rheological behaviour observed in this paper would be qualitatively comparable to the real concrete mixes. Based on the results, the following conclusions can be drawn:

- All pastes showed high fluidity immediately after mixing with a spread diameter of $240 \mathrm{~mm}$. However, the fluidity of pastes was decreased sharply over time for the pastes made of higher amounts of GGBFS due to the CaO-rich source that leads to more early age gel formation in these pastes. 
- All pastes showed a Newtonian-like behaviour with a very small yield stress, being described very well with the Bingham model.

- The angular shape of GGBFS resulted in an increase in the yield stress and plastic viscosity due to the particleparticle interactions.

- The high concentrations of silicate in the activating solution increase in the shear forces between particles. Consequently, a significant increase in the plastic viscosity was recorded for the pastes made of an activator with higher viscosity.

- Viscosity and yield stress for AAM pastes were gradually increased over time due to the formation of more interparticle geopolymer gels and the flocculation process.

Overall, when a shear force is imposed on the AAM paste, the particle roughness and the viscous effect of the activator are the factors that affect the relative motion of particles and the consequent rheological parameters. However, the very low yield stress found for all AAM pastes in our study implies the dominance of the hydrodynamic force.

\section{CRediT authorship statement}

Mohammed Fouad Alnahhal: Conceptualization, Methodology, Validation, Formal analysis, Investigation, Data Curation, Writing - original draft, Visualization.

Taehwan Kim: Conceptualization, Methodology, Validation, Resources, Writing - review and editing, Supervision, Project administration, Funding acquisition.

Ailar Hajimohammadi: Methodology, Validation, Writing review and editing, Supervision.

\section{References}

[1] J.J. Biernacki, J.W. Bullard, G. Sant, K. Brown, F.P. Glasser, S. Jones, T. Ley, R. Livingston, L. Nicoleau, J. Olek, Cements in the 21st century: Challenges, perspectives, and opportunities. J Am Ceram Soc (2017) 100 (7): 2746-2773. https://doi.org/10.1111/jace.14948

[2] J.L. Provis, A. Palomo, C. Shi, Advances in understanding alkaliactivated materials. Cem Concr Res (2015) 78: 110-125. https://doi.org/10.1016/j.cemconres.2015.04.013

[3] H.A. Khan, M.S. Khan, A. Castel, J. Sunarho, Deterioration of alkaliactivated mortars exposed to natural aggressive sewer environment. Constr Build Mater (2018) 186: 577-597. https://doi.org/10.1016/j.conbuildmat.2018.07.137

[4] B. Singh, G. Ishwarya, M. Gupta, S.K. Bhattacharyya, Geopolymer concrete: A review of some recent developments. Constr Build Mater (2015) 85: 78-90.

https://doi.org/10.1016/i.conbuildmat.2015.03.036

[5] A. Favier, J. Hot, G. Habert, N. Roussel, J.-B.d.E. de Lacaillerie, Flow properties of MK-based geopolymer pastes. A comparative study with standard Portland cement pastes. Soft Matter (2014) 10 (8): 1134-1141. https://doi.org/10.1039/c3sm51889b

[6] N. Roussel, Rheological requirements for printable concretes. Cem Concr Res (2018) 112: 76-85 https://doi.org/10.1016/j.cemconres.2018.04.005

[7] J.H. Kim, N. Noemi, S.P. Shah, Effect of powder materials on the rheology and formwork pressure of self-consolidating concrete. Cem Concr Compos (2012) 34 (6): 746-753. https://doi.org/10.1016/j.cemconcomp.2012.02.016

[8] H. Xie, F. Liu, Y. Fan, H. Yang, J. Chen, J. Zhang, C. Zuo, Workability and proportion design of pumping concrete based on rheological parameters. ConstrBuild Mater (2013) 44: 267-275. https://doi.org/10.1016/j.conbuildmat.2013.02.051

[9] D. Feys, R. Cepuritis, S. Jacobsen, K. Lesage, E. Secrieru, A. Yahia, Measuring rheological properties of cement pastes: most common techniques, procedures and challenges. RILEM Tech Lett (2018) 2: 129-135. https://doi.org/10.21809/rilemtechlett.2017.43

[10] M. Alonso, S. Gismera, M. Blanco, M. Lanzón, F. Puertas, Alkaliactivated mortars: Workability and rheological behaviour. Constr Build Mater (2017) 145: 576-587. https://doi.org/10.1016/j.conbuildmat.2017.04.020

[11] C. Montes, D. Zang, E.N. Allouche, Rheological behavior of fly ashbased geopolymers with the addition of superplasticizers. J Sust CemBased Mater (2012) 1 (4): 179-185. https://doi.org/10.1080/21650373.2012.754568

[12] F. Puertas, C. Varga, M. Alonso, Rheology of alkali-activated slag pastes. Effect of the nature and concentration of the activating solution. Cem Concr Compos (2014) 53: 279-288. https://doi.org/10.1016/j.cemconcomp.2014.07.012

[13] Y. Rifaai, A. Yahia, A. Mostafa, S. Aggoun, E.-H. Kadri, Rheology of fly ash-based geopolymer: Effect of $\mathrm{NaOH}$ concentration. Constr Build Mater (2019) 223: 583-594. https://doi.org/10.1016/j.conbuildmat.2019.07.028

[14] A. Favier, G. Habert, J.d.E. de Lacaillerie, N. Roussel, Mechanical properties and compositional heterogeneities of fresh geopolymer pastes. Cem Concr Res (2013) 48: 9-16. https://doi.org/10.1016/j.cemconres.2013.02.001

[15] Q. Yuan, D. Zhou, K.H. Khayat, D. Feys, C. Shi, On the measurement of evolution of structural build-up of cement paste with time by static yield stress test vs. small amplitude oscillatory shear test. Cem Conc Res (2017) 99: 183-189. https://doi.org/10.1016/j.cemconres.2017.05.014

[16] K. Kondepudi, K.V. Subramaniam, Rheological characterization of low-calcium fly ash suspensions in alkaline silicate colloidal solutions for geopolymer concrete production. J Clean Prod, (2019) 234: 690701. https://doi.org/10.1016/j.jclepro.2019.06.124

[17] H. Mehdizadeh, E.N. Kani, Rheology and apparent activation energy of alkali activated phosphorous slag. Constr Build Mater (2018) 171: 197-204. https://doi.org/10.1016/j.conbuildmat.2018.03.130

[18] T. Yang, H. Zhu, Z. Zhang, X. Gao, C. Zhang, Q. Wu, Effect of fly ash microsphere on the rheology and microstructure of alkali-activated fly ash/slag pastes. Cem Concr Res (2018) 109: 198-207. https://doi.org/10.1016/j.cemconres.2018.04.008

[19] K. Vance, A. Dakhane, G. Sant, N. Neithalath, Observations on the rheological response of alkali activated fly ash suspensions: the role of activator type and concentration. Rheologica Acta (2014) 53 (1011): 843-855. https://doi.org/10.1007/s00397-014-0793-z

[20] J.H. Kim, H.J. Yim, R.D. Ferron, In situ measurement of the rheological properties and agglomeration on cementitious pastes. J Rheol (2016) 60 (4): 695-704. https://doi.org/10.1122/1.4954251

[21] Z. Tan, S.A. Bernal, J.L. Provis, Reproducible mini-slump test procedure for measuring the yield stress of cementitious pastes. Mater Struct (2017) 50 (6): 235. https://doi.org/10.1617/s11527-017-1103-x

[22] D.-W. Zhang, D.-m. Wang, Z. Liu, F.-z. Xie, Rheology, agglomerate structure, and particle shape of fresh geopolymer pastes with different $\mathrm{NaOH}$ activators content. Constr Build Mater (2018) 187: 674-680. https://doi.org/10.1016/j.conbuildmat.2018.07.205

[23] D.-W. Zhang, K.-F. Zhao, F.-z. Xie, H. Li, D.-m. Wang, Effect of waterbinding ability of amorphous gel on the rheology of geopolymer fresh pastes with the different $\mathrm{NaOH}$ content at the early age. Constr Build Mater (2020) 261: 120529. https://doi.org/10.1016/j.conbuildmat.2020.120529

[24] T. Revathi, R. Jeyalakshmi, Fly ash-GGBS geopolymer in boron environment: A study on rheology and microstructure by ATR FT-IR and MAS NMR. Constr Build Mater (2020): 120965. https://doi.org/10.1016/j.conbuildmat.2020.120965

[25] A. Poulesquen, F. Frizon, D. Lambertin, Rheological behavior of alkaliactivated metakaolin during geopolymerization. J Non-Crystalline Solids (2011) 357 (21): 3565-3571. https://doi.org/10.1016/j.jnoncrysol.2011.07.013

[26] K. Vance, G. Sant, N. Neithalath, The rheology of cementitious suspensions: a closer look at experimental parameters and property determination using common rheological models. Cem Concr Compos (2015) 59: 38-48. https://doi.org/10.1016/i.cemconcomp.2015.03.001

[27] A.M. Mostafa, A. Yahia, New approach to assess build-up of cementbased suspensions. Cem Concr Res (2016) 85: 174-182. https://doi.org/10.1016/j.cemconres.2016.03.005

[28] T. Huang, Q. Yuan, F. He, Y. Xie, Understanding the mechanisms behind the time-dependent viscoelasticity of fresh C3A-gypsum paste. Cem Concr Res (2020) 133: 106084. https://doi.org/10.1016/j.cemconres.2020.106084 
[29] T.R. Muzenda, P. Hou, S. Kawashima, T. Sui, X. Cheng, The role of limestone and calcined clay on the rheological properties of LC3. Cem Concr Compos (2020) 107: 103516.

https://doi.org/10.1016/j.cemconcomp.2020.103516

[30] J.H. Kim, H.R. Jang, H.J. Yim, Sensitivity and accuracy for rheological simulation of cement-based materials. Comp Concr (2015) 15 (6): 903-919. https://doi.org/10.12989/cac.2015.15.6.903

[31] S.Y. Oderji, B. Chen, M.R. Ahmad, S.F.A. Shah, Fresh and hardened properties of one-part fly ash-based geopolymer binders cured at room temperature: Effect of slag and alkali activators. J Clean Prod (2019) 225: 1-10. https://doi.org/10.1016/j.jclepro.2019.03.290

[32] M.O. Yusuf, M.A.M. Johari, Z.A. Ahmad, M. Maslehuddin, Impacts of silica modulus on the early strength of alkaline activated ground slag/ultrafine palm oil fuel ash based concrete. Mater Struct (2015) 48 (3): 733-741. https://doi.org/10.1617/s11527-014-0318-3

[33] A. Allahverdi, E.N. Kani, S. Esmaeilpoor, Effects of silica modulus and alkali concentration on activation of blast-furnace slag. Iranian J Mater Sci Eng (2008) 5 (2): 32-35.

[34] J. Xiang, L. Liu, X. Cui, Y. He, G. Zheng, C. Shi, Effect of limestone on rheological, shrinkage and mechanical properties of alkali-Activated slag/fly ash grouting materials. Constr Build Mater (2018) 191: 12851292. https://doi.org/10.1016/j.conbuildmat.2018.09.209

[35] D.P. Bentz, C.F. Ferraris, M.A. Galler, A.S. Hansen, J.M. Guynn, Influence of particle size distributions on yield stress and viscosity of cement-fly ash pastes. Cem Concr Res (2012) 42 (2): 404-409. https://doi.org/10.1016/j.cemconres.2011.11.006

[36] P. Coussot, C. Ancey, Rheophysical classification of concentrated suspensions and granular pastes. Physical Review E, (1999) 59 (4): 4445. https://doi.org/10.1103/PhysRevE.59.4445

[37] Z. Zhang, H. Wang, J.L. Provis, F. Bullen, A. Reid, Y. Zhu, Quantitative kinetic and structural analysis of geopolymers. Part 1 . The activation of metakaolin with sodium hydroxide. Thermochimica Acta (2012) 539: 23-33. https://doi.org/10.1016/j.tca.2012.03.021

[38] N. Roussel, A. Lemaître, R.J. Flatt, P. Coussot, Steady state flow of cement suspensions: A micromechanical state of the art. Cem Concr $\operatorname{Res}(2010) 40$ (1): 77-84

https://doi.org/10.1016/j.cemconres.2009.08.026

[39] A. Favier, J. Hot, G. Habert, J.d.E. de Lacaillerie, N. Roussel, Rheology of geopolymer: comparative study between Portland cement and metakaolin based geopolymer. 1st RILEM International Conference on Rheology and Processing of Construction Materials., RILEM Publications sarl, Paris: France, 2013, 49-56.

[40] [40] F. Rubio-Hernández, A. Adarve-Castro, J. Velázquez-Navarro, N. Páez-Flor, R. Delgado-García, Influence of water/cement ratio, and type and concentration of chemical additives on the static and dynamic yield stresses of Portland cement paste. Constr Build Mater (2020) 235: 117744

https://doi.org/10.1016/i.conbuildmat.2019.117744

[41] N. Roussel, G. Ovarlez, S. Garrault, C. Brumaud, The origins of thixotropy of fresh cement pastes. Cem Concr Res (2012) 42 (1): 148157. https://doi.org/10.1016/j.cemconres.2011.09.004 